\title{
Perguntas e processos para um ensino de leitura literária inovador
}

\author{
Rosiane Xypas*
}

\begin{abstract}
Resumo: O objetivo deste artigo é duplo. Por um lado, refletir sobre o ensino da leitura literária vista como processo, ressaltando os processos afetivo e simbólico da linguagem. Por outro, refletir sobre a elaboração de perguntas na atividade de leitura literária que permitam respostas provenientes da cabeça do leitor. As recentes teorias da leitura de textos literários favorecem um ensino engajado na categorização de atitudes e interesses do leitor pelo texto lido destacando sua subjetividade no ato de ler.
\end{abstract}

Palavras-chave: Leitura literária. Processo. Questões.

Abstract: The purpose of this paper is twofold. On one hand, it reflects upon the teaching of literary reading seen as a process, emphasizing the affective and symbolic processes of language. On the other hand, it reflects upon the elaboration of questions during the literary reading activity that allow responses from the readers head. Recent theories of reading literary texts favor a teaching method engaged in categorizing the reader's attitudes and interests towards the readen text, highlighting the role of subjectivity in the act of reading.

Keys-words: Literary reading. Process. Questions.

Résumé : L'objectif de cet article est double. D'une part, réfléchir sur l'enseignement de la lecture vue comme processus. On met en exergue les processus affectifs et symbolique du langage. De l'autre, réfléchir sur l'élaboration des questions dans l'activité de lecture littéraire qui permettent réponses que peuvent venir de la tête du sujet lecteur. Les nouvelles théories de lecture de textes littéraires favorisent un enseignement engagé dans la catégorisation des attitudes et d'intérêts du lecteur pour le texte lu afin de mettre en relief sa subjectivité dans l'acte de lire.

Mots-clés : Lecture littéraire. Processus. Questions.

\section{Introdução}

\footnotetext{
* Professora e pesquisadora do Departamento de Letras da UFPE. Atua no ensino-aprendizagem de Francês como Lingua Estrangeira com ênfase em Língua, Literatura e seu ensino. http://orcid.org/oooo0002-4296-5981
}

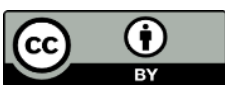

Este artigo está licenciado sob forma de uma licença Creative Commons Atribuição 4.0 Internacional, que permite uso irrestrito, distribuição e reprodução em qualquer meio, desde que a publicação original seja corretamente citada. 
Este artigo propõe uma reflexão tanto sobre a leitura literária vista como processo quanto sobre as perguntas para seu ensino. Coloca-se em destaque a implicação do leitor comum como elemento essencial no ensino. O fio condutor desta problemática é, então, a utilização da leitura subjetiva no ensino da literatura considerada fundamental para que a aprendizagem da leitura literária vá, como diz Louichon e Rouxel (2010a, p. 10) além de "uma lógica acumulativa para uma lógica associativa". E isso só é possível se se acolhe a subjetividade do leitor comum lendo através de atividades que propiciem a explicitação de sua singularidade e criatividade desencadeadas durante a leitura literária.

O papel na formação de leitores literários é mobilizar o aluno para essa lógica associativa que é procurar saber o que acontece quando ele lê um livro, impulsionandolhe a viver uma experiência interior. Essa experiência é considerada superior à exterior vivida por ele, inclusive a de compartilhamento de uma obra lida entre seus pares na sala de aula. Ora, a leitura literária vista como processo, agrega à literatura uma representação de construto social e afetivo e o leitor um construtor de sentidos. Estes sentidos são respostas a si, ou seja, uma apropriação criativa e singular daquele que lê (XYPAS, 2018a). Como diz Macé (2011, p.14) “a leitura literária implica em uma conduta estética, um caminho mental, físico e afetivo advindo da linguagem”. Assim, a premissa é que fazer avançar o ensino da leitura literária, é elaborar questões para a leitura de textos literários que desenvolvam os processos interpretativos do sujeito leitor lendo.

Vale ressaltar que, nas teorias sobre leitura, até meados dos anos 8o, o modelo predominante de leitura era baseado no texto e o papel do leitor era o de responder o que o autor quis dizer. Depois, a leitura passa a ser um modelo interativo. Nos anos 9o, o leitor constrói os sentidos do texto lido, sem que para isso, admitam os especialistas da literatura que toda interpretação seja válida. Nos anos 200o, o modelo de leitura se fundamenta no acolhimento da subjetividade do sujeito leitor, a leitura subjetiva entra no ensino da literatura e dá voz ao leitor comum, elemento mais esquecido nos estudos literários.

O leitor é aquele que tem um status, e tanto o seu papel quanto suas atitudes, histórias, grupos de referência entram em jogo na recepção da leitura (MOIRAND, 1979). Atualmente, não se pode negar que o texto lido produz um efeito sobre o leitor comum, 
um efeito que nem sempre é o imaginado pelo autor porque atrelado aos objetivos de leitura deste leitor que, por usa vez, traz consigo grande bagagem de experiência de vida. Assim, este faz no mínimo dois movimentos: emissões de hipóteses e projeção no lido segundo o seu mundo.

Entende-se que o leitor é uma variável e constitui, certamente, a mais complexa do modelo de compreensão, e deve ser levado em conta na hora do ensino de leitura literária. O professor não deve esquecer que o leitor aborda, como diz Giasson (1990, p. 9) “as tarefas de leitura com as estruturas cognitivas (fonológicas, sintáticas, semânticas e pragmáticas) e afetivas (ligadas às atitudes e ao interesse dele) que lhes são próprias viabilizando diferentes processos na atividade de compreensão".

Vista por este ângulo, as tarefas para uma atividade consciente de leitura de textos literários permitem ao leitor uma produção de efeitos implicando diversas dimensões sociais e psicológicas. Ora, saber por que se lê, é fundamental para se compreender o que se quer com a leitura. (MOIRAND, 1979, p. 19). Tudo se passa como se o leitor devesse ter objetivos de leitura e empregasse estratégias eficazes nas mesmas. Como diz Moirand (179, p. 22) "a experiência anterior do leitor influencia nos processos de compreensão”. E como fazer para despertar sua experiência anterior?

De diversas formas, mas pode-se contar com todo e qualquer elemento paratextual encontrado no entorno do texto, pois este elemento evoca a experiência vivida, o saber-fazer, a bagagem sociocultural daquele que lê. Dessa forma "a compreensão em leitura é agora percebida como um processo holístico ou unitário. Antes se tratava de uma concepção e transposição na qual o leitor fazia apenas transportar em sua memória um sentido preciso determinado pelo autor". (GIASSON, 1990, p. 24). Esta autora sugere assim, a interação do sujeito leitor na atividade, o que no antigo modelo de compreensão de leitura era um obstáculo, visto que o sentido se encontrava no texto, e era o leitor que deveria "pescá-lo". Hoje sabe-se que o sentido do texto é construído graças aos conhecimentos prévios do leitor e de sua intenção de leitura.

O modelo de leitura é tríade (texto-leitor-contexto), bastante conhecida dos estudiosos de literatura e gera estruturas e processos. Como diz ainda Giasson (1990, p.228) "globalmente, as estruturas fazem referência ao que o leitor é (seus 
conhecimentos e suas atitudes) enquanto os processos fazem referência ao que ele faz durante a leitura (habilidades postas em obra)". Entende-se que a leitura apresenta uma dupla dimensão: estrutural e processual que evoca do leitor seu corpo e sua mente. Assim, a compreensão em leitura varia entre o grau da relação entre texto-leitorcontexto e quanto mais estes estão imbricados uns nos outros, melhor será a compreensão (GIASSON, 1990, p.7).

Entende-se que as estruturas mencionadas são complementares e que para o ensino da leitura literária, o professor deveria indicar ao sujeito leitor que este deve desencadear as duas, ou seja, a estrutura cognitiva e a afetiva no ato de ler unindo emoção e cognição. Nem uma nem outra deve se sobrepor ou mesmo deixar de ser ensinada, pois esse modelo vigora desde os anos 90 na comunidade científica. Ela proporciona uma atividade vista como caminho que permite experiências. Como diz Cicurel (1991, p. 13) “a leitura literária é como uma experiência que evoca um tipo de reação afetiva, intelectual que é outra coisa que os processos cognitivos postos em prática na recepção de textos informativos”. Ao leitor deve ser ensinado que existem diferenças entre leitura de textos informativos e a de textos literários.

A postura aqui assumida influi no agir professoral que vê o ensino da leitura literária, acentuando os processos afetivos e simbólicos da leitura e a elaboração de questões que possibilitem respostas encontradas na cabeça do leitor. Enfim, a atividade da leitura literária é uma interação complexa, porque envolve o criar e recriar do objeto de arte lido colocando em foco o leitor comum lendo.

A metodologia utilizada no presente artigo, releva de uma pesquisa bibliográfica utilizando procedimentos comparativos entre artigos científicos, capítulos de livros, verbetes em dicionários consultados, indo além da mera busca de informação sobre o tema aqui tratado.

Destaca-se a pesquisa do sintagma leitura literária, procura-se ampliar a reflexão sobre perguntas para atividades de leitura literária, expõe-se resultados sobre o investimento da leitura literária como processos entrelaçados no intuito de apontar caminhos inovadores para o ensino da leitura literária. 


\section{Perguntas na sala de aula para avaliar ou ensinar a leitura literária?}

Perguntar sempre fez parte da vida cotidiana do professor e do aluno. Como diz Giasson (1990, p. 224) “perguntar sempre fez parte das estratégias de intervenção". Quando se pensa sobre as estratégias de intervenção na maioria das vezes, tem-se contentado com as que são viabilizadas para todo tipo de texto. Mas existem duas categorias maiores de perguntas: as voltadas para avaliar o aluno e as para ensinar o aluno a ler. Então, em que lugar na sala de aula colocar uma e outra, ou uma ou outra?

Em um primeiro momento, perguntas que direcionem o professor para avaliar a leitura do aluno na sala de aula são menos importantes com o texto literário. Mesmo porque não se deve entrar na sala de aula pensando que o aluno sabe ler textos literários. Logo, as mais importantes são as perguntas voltadas para o ensino. Ressalta-se que perguntas muito literais, as voltadas para busca de informações menores do texto ou as voltadas para avaliação do sujeito leitor; ou ainda, as que o professor já tem a resposta pronta na cabeça, reduzem a atividade leitora no tocante à criatividade do leitor comum.

Perguntas literais implicam pouco o sujeito leitor na atividade de leitura literária. Em que faz avançar a leitura literária, a pergunta que move o sujeito leitor para a "pesca” de sua resposta no texto? Conclui-se que perguntas literais e voltadas para busca de informações não favorecem o objetivo pessoal de leitura do aluno (GIASSON, 1990, p. 224). Se não há objetivos pessoais de leitura, não pode haver implicação na aprendizagem.

Para o ensino da leitura de textos literários, as diretrizes contemporâneas de ensino sugerem que o aluno possa tomar gosto pela atividade. Logo, temos que lançar mão de perguntas voltadas para o ensino da leitura de textos literários como molas propulsoras de um aprendizado ativo. Pergunta-se então, que tipos de questões seriam melhores para a mobilização da aprendizagem da leitura literária do aluno?

Visando melhorar o ensino de atividades da leitura literária, há pesquisas que propõem esse tipo de leitura em três momentos: antes, durante e depois. É um percurso didático para favorecer o controle avaliativo necessário ao ensino da leitura literária. 
Falou-se em perguntas, mas, o que se entende por elas? Perguntas seriam palavras ou frases interrogativas? Quem, quando, por que e onde são perguntas clássicas (GIASSON,1990, p. 225). E quem não as conhecem, em seu ofício docente? Sabe-se que toda e qualquer questão demanda trabalho mental do aluno, uma mais que outra. Em 1956, Bloom apud Giasson (1990) apresentou uma taxinomia dos níveis cognitivos que influenciaram bastante nas classificações das perguntas. Ele reuniu quatro categorias:

Reconhecimento literal ou lembrança: a questão pede ao aluno para reconhecer ideias, informações, situações ou eventos expressos explicitamente no texto.

Inferência: a pergunta requer do aluno que ele utilize uma síntese de sua compreensão literal, conhecimentos pessoais e de sua imaginação a fim de formular hipóteses.

Avaliação: a questão exige que o aluno julgue o texto, que ele distinga o real do imaginário, distinga o fato de uma opinião.

Apreciação: a questão engaja o leitor a reagir à qualidade do texto apoiando-se em seus conhecimentos das técnicas literárias que empregam os autores para suscitar reações afetivas e intelectuais nos leitores.

Como diz Giasson (1990, p. 226) "essa taxinomia é compreendida por três níveis: o da compreensão literal, interpretativa e crítica”. Fundada pelos processos cognitivos da leitura, aqui se vislumbra um papel importante para o ensino da leitura literária: o da inclusão do aluno como elaborador de perguntas. Assim, o ensino pode ampliar o leque de suas possibilidades. Mas será que reconhecer, inferir, avaliar e apreciar permitem ao aluno escapar de questões apenas avaliativas?

Pearson e Johnson em 1978 apud Giasson (1990) apresentam a particularidade de introduzir perguntas elaboradas pelos alunos sobre o texto, ligando-as às suas respostas. Busca-se assim entender quais processos foram utilizados pelos alunos para responder à pergunta elaborada por eles próprios. Poder-se-á entender porque uma pergunta é aceitável, mesmo se a resposta não fora prevista pelo professor.

A taxinomia dos autores acima mencionados compreende a relação-questãoresposta, ou seja, R-Q-R em três níveis como a taxinomia clássica: 
a) Relação explícita e textual: pergunta e resposta decorrem do texto e essa relação é claramente indicada pelos índices do texto.

b) Relação implícita e textual: pergunta e resposta decorrem do texto, mas não há índices gramaticais no texto. O leitor deve usar a inferência.

c) Relação implícita e fundada nos esquemas do leitor: a pergunta decorre do texto e o leitor utiliza seus próprios conhecimentos para responder à pergunta.

A implicação pedagógica das classificações das perguntas pode auxiliar no ensino da leitura literária, tendo em vista a inquietude do professor em relação às respostas incorretas dos alunos de questões elaboradas por ele ou pelo livro didático utilizado na sala de aula. Essas perguntas podem fazer com que os professores reprovem os alunos, podem implicar em releituras com broncas, e gerar desconforto tanto para o professor quanto para o aluno. No entanto, implicando o aluno no ensino de leitura literária, fazendo com que ele mesmo crie suas perguntas, pode ser que haja uma interação entre ele e seus pares, entre ele e seu professor, o que parece ser positivo para o desenvolvimento do ensino da leitura literária.

Dentre outras classificações de perguntas elaboradas para a leitura se encontram as de Poindexter e Prescott em 1986 apud Giasson (1990). Em 1986, Raphael propõe, inspirado em Pearson e Johnson (1978), procedimentos voltados para a sensibilização dos alunos. Raphael (1986) apud Giasson (1990, p. 230) afirma que "a resposta a uma pergunta nem sempre é dada explicitamente por uma frase do texto". Tem-se a relação R-Q-R advinda de Pearson e Johnson (1978) acrescida agora de duas categorias de respostas segundo Raphael: 1) as respostas que se encontram no texto; 2) as respostas que provêm da cabeça do leitor.

Para as respostas que se encontram no texto, o autor apresenta duas categorias: a do Está aqui e a de Pense e procure. Quanto às respostas que provêm da cabeça do leitor, Raphael apresenta as categorias: o autor e você e a da categoria Apenas você. Dito com outras palavras, a categoria do Está aqui compreende que a resposta se encontra em uma frase do texto; a Pense e procure compreende que a resposta está no texto, mas precisa ser procurada em várias frases do texto. E no tocante à resposta que provém da cabeça 
do leitor, temos as categorias: o autor e você, ou seja, combine o que você sabe e o que o autor diz; e a categoria Apenas você, induza o aluno a utilizar seus próprios conhecimentos.

Como diz Giasson (119o, p. 232) "antes da leitura do texto, o professor fará perguntas ao aluno do tipo que desenvolva a categoria apenas você”. O leitor utilizará seus próprios conhecimentos prévios para dar respostas. Embora Raphael tenha ampliado a taxinomia das perguntas, pensa-se que o foco recai sobre uma reflexão de perguntas que se voltam para o produto e as que se voltam para os processos. Porém, como distingui-las e como utilizá-las para o ensino da leitura literária?

Foi em 1979, que Durkin apud Giasson (1990), observou durante os momentos da leitura que as perguntas ocupavam um espaço importante durante sua realização. Este autor fez a seguinte reflexão: Se a pergunta permite ao leitor evoluir em suas reflexões sobre sua compreensão de texto, estamos diante de perguntas que visam ao ensino. Se o professor faz perguntas, no entanto, que lancem mão de ignorar o que foi respondido pelo leitor ou se o professor se limita a dizer que a resposta é exata ou não, estaremos diante de perguntas que visam à avaliação (DURKIN, 1979 apud GIASSON, 1990).

O professor precisa refletir se ele elabora perguntas no intuito de ajudar o aluno a evoluir em seus processos interpretativos, ou seja, as que promovem o ensino, ou se são perguntas que visam à avaliação do aluno sobre o certo e errado. Vale ressaltar que perguntas que se veem avaliativas são do tipo "Qual o nome de?"; "Onde se passa a história?” As que se voltam para o ensino da compreensão em leitura literária são “O que te faz dizer que..."?, “O que você precisa saber para compreender a frase?", "Neste parágrafo, o que significa...?”, “O que permitiu você predizer o que aconteceu?”, “O que faz você gostar da história?" entre outras.

Assim, as perguntas relativas às avaliações requerem do aluno a busca da resposta que ele não constrói, pois ela está no texto explicitamente. Enquanto as de ensino, vão desencadear respostas voltadas para a reflexão de seus processos de construção de sentidos. Não seriam essas questões as mais propícias para desenvolver os aspectos singulares da compreensão do sujeito leitor sobre o lido? Todavia, a elaboração de questões advém dos objetivos do ensino da leitura literária estabelecidos pelo professor. 
No ensino de uma estratégia de leitura, deve-se elaborar perguntas voltadas para o processo. Ora, se o professor deseja trabalhar o conteúdo do texto, deve-se elaborar perguntas sobre o produto. Mas tudo isso depende do objetivo do ensino. (IRWIN 1986 apud GIASSON, 1990). Além do mais, existem procedimentos sobre o questionamento recíproco, que é aquele voltado para pergunta-resposta-avaliação em uma dinâmica na qual o aluno pergunta ao professor e aos seus pares e eles respondem. Mas também, o professor pergunta aos alunos e intervém sobre as respostas destes.

Cria-se assim, um tipo de atividade que lança mão de diálogos sobre o texto, por exemplo, lido silenciosamente. Todos os leitores compartilham um mesmo objetivo de leitura: predizer (consiste em antecipar o que virá em seguida no texto); elaborar perguntas (permite aos alunos descobrir gradualmente o que pode fazer o essencial de uma boa pergunta); resumir (é uma maneira de integrar a informação, expor os elementos mais importantes, como por exemplo, os de um parágrafo,) e esclarecer o texto (um modo de chamar a atenção do leitor sobre o fato de ele saber se compreendeu ou não o texto lido).

Em resumo, elaborar questões faz parte de estratégias de intervenção docente, mas os discentes podem igualmente elaborar suas perguntas. A questão central seria elaborar questões tanto voltadas para a avaliação quanto para o ensino. No entanto, ressalta-se que a ênfase deve ser dada para as questões sobre o ensino dentro da sala de aula e algumas poucas voltadas para a avaliação. Assim, processo e produto seriam devidamente contemplados. Entende-se que se constroem saberes com as questões advindas, do que se apresenta no texto e as que se encontram na cabeça do leitor. Não se pode esquecer que os processos de compreensão em leitura literária explicitam as habilidades postas em obra durante a pré-leitura, a leitura e a pós-leitura.

Por fim, essas reflexões podem ajudar nas elaborações de questões para desenvolver o ensino da leitura literária. Mas, leitura literária existe? E o que se entende quando se fala em leitura literária?

\section{Leitura literária ou só leitura?}


O termo leitura vem do latim lectura substantivo feminino que significa, segundo o Aurélio (2010): 1. ato, arte ou hábito de ler. 2. Aquilo que se lê. 3. Operação de percorrer, em um meio físico, marcas codificadas (as informações registradas) e fazê-las voltar à forma anterior (como imagens, sons dados para o processamento).

A primeira palavra lida na definição do termo leitura, é ato. Mas também arte ou hábito. O foco está nos processos de leitura. Esta é definida como tudo aquilo que se lê, abrindo a perspectiva geral sobre o ato de leitura. Se for assim, se incluem a leitura de imagens fixas e em movimento, placas de avisos etc. Enfim, a leitura é definida, no dicionário, como uma operação de percorrer em um meio físico marcas codificadas e fazê-las voltar à forma anterior. O Aurélio define a leitura em geral, essas definições são válidas também no tocante à leitura literária? Pelo objeto de arte próprio neste estudo, pensa-se que não. Por isso, pesquisou-se em dicionários específicos de termos literários a palavra-chave em questão, ou seja, leitura.

A surpresa na pesquisa é que se constata que nem o Guide des idées littéraires (BENAC, 1988), nem o Dicionário de termos literários (MOISÉS, 2013) conceituam a palavra leitura, e muito menos, se encontra o adjetivo literária nos mesmos. Ressalta-se, no entanto, que nos fins dos anos 8o, a psicologia cognitiva começava apenas a divulgar seus trabalhos sobre leitura. Mas, por que no dicionário literário de Moisés em 2013, não consta a definição do sintagma leitura literária? Entende-se com isso, que ou o termo não seja de fácil apreensão ou se pensa nele como sinônimo do termo leitura.

Indo além, encontram-se, no Vocabulaire de l'analyse littéraire (AMON e BOMATI, 2002) duas ocorrências da palavra em questão. A leitura literária pode ser analítica e/ou cursiva. Ela é vista como duas formas diferentes de atividade. Tem-se a leitura analítica como um exercício escolar que consiste em analisar um texto com método e rigor e a apresentá-lo sob a forma de um seminário. E a leitura cursiva como um processo de leitura praticada, tanto em sala de aula quanto fora dela, leitura destinada a motivar a leitura literária. (AMON e BOMATI, 2002, p. 261-262).

Assim, ler analiticamente um texto literário é lê-lo com método e rigor, logo fazer uma leitura objetiva do texto lido, enquanto a leitura cursiva pretende motivar os alunos a ler literatura. Tudo se passa como se a leitura analítica impusesse ao sujeito leitor uma 
abordagem técnica e objetiva dos textos e a leitura cursiva, uma leitura prática mais livre e mais corrente da leitura literária.

No Le dictionnaire du littéraire (Roy, 2002/2004) - que contém um total de 647 verbetes e que trata de diversos termos literários - apresenta o termo leitura como segue: "ler é decifrar signos escritos em voz alta ou silenciosamente". (ROY, 2002/2004, p. 338). No entanto, o leitor é surpreendido com tal conceito, já que está atrelada ao adjetivo literária. Ora, a leitura é vista como uma atividade de decifração de signos escritos, muito pouco ou superficial para o que demanda do sujeito leitor a leitura literária, pois este diante de textos literários não é o mesmo leitor diante de textos informativos.

Pensar na leitura literária como processo implica pensar que o professor não entende esse tipo de leitura como decifração de signos. Caso contrário, há estagnação no conceito por uma representação visual da leitura, ou seja, ler não passa de processo perceptivo. Ler não é apenas decifrar, deve-se ir mais além, o professor precisa, nesse caso, ampliar seu conceito do termo leitura em geral, e o de leitura literária, em particular. Avançando ainda mais no conceito de leitura encontrado no Le dicionnaire du littéraire (2002a/2004), entende-se que ela é vista como atividade que postula uma compreensão imediata do texto, mas também pode implicar em uma competência interpretativa particular, elaborada e criativa.

Essa definição amplia um pouco mais a representação da leitura literária vista como uma atividade mental e dinâmica que por mais que o corpo físico daquele que lê se mova pouco, que pareça estático, a dinâmica não deixa de existir. Pensa-se, de fato, na atividade de leitura como aquela que surpreende o leitor positiva ou negativamente, porque o sensibiliza. Ela pode até influenciar no comportamento dele, demonstrando reações ostensivas, como jogar o livro contra a parede, ou mais implicando atitudes mais sutis, como encher os olhos de lágrimas por uma emoção que se aflora por uma ou demais passagens lidas.

Para ampliar a reflexão sobre o sintagma leitura literária, duvida-se que apenas a ligação do autor e o do texto faça um bom leitor. Introduz-se aqui o elemento ainda pouco analisado nos estudos literários: o leitor. Agora este vai figurar entre o autor e o texto. Primeiramente, a de um leitor expert, e segundamente, a de um leitor comum. 
É graças ao leitor comum, que se busca entender o sintagma leitura literária. No Dictionnaire de didactique de la littérature, como diz Dufays e Daunay (2020, p.74) “atribui-se a primeira utilização do sintagma 'leitura literária' a Maurice Blanchot (1943/1954). A leitura literária é uma exigência endereçada ao leitor, uma condição de possibilidade da ilusão que é o mundo literário". Nesses aspectos, pode-se inferir que a leitura literária se diferencia da leitura de outros tipos de textos. Parece está marcada pela oposição entre leitura referencial e leitura literária. Leitura que faz entrar o leitor na ficção para diferenciar da leitura que o traz à realidade. Mas que esse movimento, entrada na ilusão, saída da realidade não implique em uma leitura literária cortada da vida. Pelo contrário, pois atrelada à Literatura, a leitura literária não deve cortar o sujeito leitor da vida real dele. Mas abrir caminhos para encarar esta, de outras maneiras.

A leitura, tanto ativa a memória do sujeito leitor quanto a faz falhar. Assim, a leitura literária pode ser pensada como um jogo que impõe fugas a regras de análises puramente objetivas, porque angaria novas emoções e desperta emoções adormecidas. Ela faz manifestar a subjetividade do leitor que deve ser levada em conta no ensino. Com efeito, a leitura literária faz oscilar a memória-afetiva entre lembranças e esquecimentos e nos preenchimentos do vazio deixado pelos textos literários. Enfim, essa atividade modifica o lido, por um lado, pois nenhum livro permanece igual após a sua leitura, e por outro, modifica o leitor, que não sai imune dos registros literários lidos.

Conclui-se que a leitura literária não deve se limitar a ser vista e utilizada como um processo de decifração de signos escritos. Esse processo é apenas uma etapa introdutória, por isso insuficiente, para se adentrar no universo literário. Assim, no tocante ao sintagma leitura literária encontrado nos dicionários consultados, pode-se dizer que eles não esclarecem muito sobre a questão, mas permitem refletir um pouco sobre a mesma. O que faltou nos conceitos lidos foi uma reflexão sobre a dimensão subjetiva manifestada na leitura literária de todo leitor comum e assim proporcionar saberes aos estudiosos sobre o que diz o texto literário a este tipo de leitor e saber o que o texto lhe fala à emoção. Para tal, pensa-se que abordar a leitura literária como processo e focalizar nos processos afetivos e simbólicos da linguagem, seja um modo mais propício ao desenvolvimento de um leitor comum implicado em sua leitura. 


\section{A leitura literária e seus processos no ensino: o processo perceptivo}

Admitindo que a leitura literária se constitui em seus cinco processos, a saber, perceptivo, cognitivo, argumentativo, afetivo e simbólico, a primeira pergunta que surge à mente, é a seguinte: Seriam uns mais importantes que outros, ou seja, há uns processos que implicam mais o leitor na atividade leitora que outros?

O primeiro processo de leitura literária é o perceptivo. Como diz Thérien (2007, p. 25) "se eu leio uma carta endereçada a mim por alguém que amo, sua assinatura por exemplo, evocará imediatamente imagens mentais. (...) é um dado de linguagem que deve ser percebido, a língua escrita”. Segundo este autor, esse processo desencadeia imagens mentais no ato de ler, e neste caso, a evocação é introduzida pela memóriaafetiva que sustém a atividade, lembrança despertada, graças ao sentimento acordado à assinatura. Vale ressaltar que a memória aqui falada, não é aquela que faz avançar a leitura, como, por exemplo, a de trabalho. Aqui a memória que foi despertada se esbarra em uma outra mais antiga despertando emoção no sujeito leitor. É a ação da forma que desperta emoções confirmando um ensino associativo como mencionado na introdução deste artigo.

Ainda falando sobre o processo perceptivo entram em jogo essencialmente as formas visíveis da escrita tipográfica e a significação que apresentam habitualmente as maiúsculas, os itálicos, as representações gráficas da língua lida, as disposições do texto sobre as páginas etc (THÉRIEN, 2007, p. 26). O valor acordado ao que se chama gênero literário como poema, conto, novela, romance, carta podem desencadear no sujeito leitor a mesma percepção e a mesma recepção? A resposta é negativa. Percebe-se o poema e o conto de forma diferente porque eles têm formas diferentes. Consequentemente, lê-se da mesma maneira? Pouco provável. Em leitura literária a diferença encontrada na forma do texto sugere mudanças mentais. Desse modo, as

\footnotetext{
${ }^{1} \mathrm{O}$ artigo que nos incita a abordagem do ato de leitura como processo se intitula $L$ 'exercice de la lecture littéraire. Ele é originário do artigo Pour une sémiotique de la lecture que Gilles Thérien escreveu nos anos 1990 para a Revista Protée. O autor em questão afirma que modificou o título em 2007 introduzindo a palavra literária no seu artigo e apresentando a evolução de seu pensamento sobre o ato de ler.
} 
perguntas que associem paratextos editorias, como títulos, nome do autor(a), capa, quarta capa entre outros, pelas quais o leitor comum possa se projetar, pode ser que haja certo engajamento dele no ato da leitura literária.

Ressalta-se que elementos a serem explorados no processo perceptivo pode ser o incipit, elemento paratextual pelo qual o sujeito leitor poderá privilegiar a forma do texto. O processo perceptivo permite ler a capa, suas cores, julgadas no conjunto, atraentes ou não, aos títulos que chamam atenção ou não, ao nome do(a) autor(a) que escreveu a história e a corrente literária ao qual está filiado(a), o gênero em que foi escrito, estes elementos poderão desencadear imagens mentais singulares de cada leitor. Devem ser colhidas essas imagens mentais singulares, é nisso também que consiste o avanço da leitura literária nos tempos de hoje com a introdução da leitura subjetiva no ensino da literatura.

No entanto, reduzir o ensino da leitura literária ao desenvolvimento do processo perceptivo é permitir que o sujeito leitor fique no entorno do texto e não na leitura do texto propriamente dito. O perigo disso é que ele não se envolva e nem deseje se engajar na leitura, afinal de contas, o processo perceptivo é um tratamento de baixo nível, comparado aos tratamentos mnésicos que são considerados de alto nível na leitura.

Enfim, tais aspectos são superficiais e insuficientes para a formação leitora. Mas, como impulsionar o sujeito leitor a ir mais além? Em uma tomada de consciência de exercícios de compreensão interpretativa dos processos cognitivos?

\section{O processo cognitivo da leitura literária}

O segundo processo proposto por Thérien (2007) é o processo cognitivo pelo qual a leitura literária ajudará o sujeito leitor a constituir um saber, uma cultura, uma erudição que tende a aumentar e a se diversificar com suas leituras e que poderá se tornar a marca de seu interesse pela literatura na formação de sua biblioteca interior. Esta vista como "um espaço psicológico, linguístico e social, [que pode] estruturar o sujeito leitor em sua vida inteira”. (XYPAS, 2019, p. 80). 
Se esse processo for o responsável por construir o saber, ele demanda unidade e coerência. Vale ressaltar que a unidade de compreensão do discurso não é a frase, como diz Thérien (2007, p. 28), "mas o quadro cognitivo que faz avançar a leitura. Porém, não se constrói um saber, não se aumenta a cultura restringindo-se apenas à compreensão. O limite desta, em relação à interpretação, é que ela se ancora no processo perceptivo e no júbilo da argumentação. Em leitura literária, o sujeito leitor precisa saber que interpretar é sempre uma atividade mais ampla porque contribui para a mudança do regime da compreensão iniciando o sujeito leitor em uma descentração sobre o lido. Em outras palavras, ela favorece o encontro com o outro diferente de si. É com a interpretação, que ele tem a possibilidade de romper a barreira da ficção e voltar para a realidade. Por fim, admitindo interpretar, como a busca do descobrimento dos sentidos latentes de um texto, e não os aparentes, a interpretação releva de uma leitura nas entrelinhas do escrito, e nunca ou quase nunca, permanecerá o leitor no sentido literal do texto.

A interpretação favorece diversas leituras do texto literário e é preciso ensinar que não se pode ler textos literários, por exemplo, impressionado pelo peso do nome do(a) autor(a) ou das impressões dos críticos sobre a obra, não em um primeiro momento da leitura. Uma vez que se ensina aos aprendizes a compreender que esses fatos são menos importantes durante a leitura, eles estarão sendo ajudados a pensarem por si mesmos. Como diz Woolf (2019, p.73) "pois não há nada mais fatal do que sermos guiados por preferências alheias em um assunto tão pessoal”.

Vale ressaltar que o processo cognitivo tem sido a varinha mágica na atividade de leitura literária, porque quando se pensa em cognição se pensa em conhecimento. Como diz, Klinkenberg (2002a, p. 104) "a literatura apresenta processo cognitivo quando gera conhecimentos". Uma pergunta surge: Promovem-se conhecimentos com leitura de texto literário? Se sim, de que tipo de conhecimento se fala?

Houve uma época em que a literatura queria ser vista como ciência, mergulhando totalmente em um racionalismo profundo. É preciso entender que a arte da palavra gera conhecimentos próprios, pontos de vista sobre um mesmo fato desviando o sujeito leitor da morte do pensamento único. Então, mesmo que a leitura literária se nutra da 
cognição daquele que lê, este processo não deve se limitar a engendrar um saber, porque é próprio do texto literário gerar saberes.

Por fim, vale ressaltar que, quando se trata de leitura literária, a palavra cognição está atrelada, desde a metade do século XX, ainda como diz Klinkenberg (2002a, p. 103) "as ciências cognitivas, onde convergem a neurologia, a genética, a antropologia, a psicologia, a sociologia, a informática, as ciências da linguagem, sobretudo a filosofia da linguagem e a semiótica”. É possível que graças às ciências aqui mencionadas, o termo cognitivo tenha evoluído para atender as demandas do contexto no qual está inserido.

Enfim, o processo cognitivo é fundamental, porque dentre outras coisas como se viu até o momento, ele pode levar o leitor a refletir sobre as estratégias cognitivas usadas durante a leitura, a saber, "repetição, tomada de notas, dedução, indução, resumo, inferência etc", segundo Cyr (1998, p.39). Todavia, não se pode parar nele quando se trata do ensino de leitura literária, esse tipo de leitura demanda muito mais.

\section{O processo argumentativo na leitura literária}

O processo argumentativo afeiçoa vários professores de literatura: a jubilação da narração. Nunca a prosa foi tão utilizada para ensinar os alunos, a argumentação, inclusive, e que pena, nos dias de hoje, ainda mesmo com diversos pesquisadores da comunidade científica de teóricos literários terem demonstrado que os processos de leitura literária devem ir além dos da argumentação.

A narração é vista como pretexto em vários trabalhos acadêmicos, notadamente com fábulas. Mas, por que não, diriam uns? E por que sim, diriam outros? O argumento nega a perspectiva de uma leitura literária íntima e singular.

Segundo Amon e Bomati (2002, p. 50), a argumentação "pode ser explícita se expõe claramente suas teses e apresenta provas convincentes, ou implícitas quando dissimula, às vezes suas intenções e seu dispositivo de persuasão”. A argumentação, como diz Amossy (2002, p. 22), "compreende meios verbais que permitem em diversas áreas, importar ou reforçar a adesão do auditório a uma tese ou a uma visão das coisas”. 
Conceito simplista e inquietante. Reforçar a visão única das coisas? O texto literário é limitado a uma visão única de adesão a uma tese?

A argumentação se desenvolve com um orador que se endereça ao seu auditório com argumentos, no intuito de lhes persuadir ou convencer. Voltada para os estudos da comunicação nos anos 70, ela se abre para a busca de um certo tipo de conclusão. Choque de paradigmas, pois o texto literário nem comunica, nem informa. Então, utilizar o texto literário para se trabalhar a argumentação, promove-se, pois, indiretamente a ideia do pensamento único da literatura. Como diz Marcuschi (2008, p. 69), "fazendo com que o indivíduo que fala seja porta-voz. Ele não fala, mas sim um discurso que fala por ele. (...) como piadas que veiculam o mesmo ponto de vista”.

Como diz ainda Amossy (2002, p. 23) "o sentido é concebido como uma direção, uma orientação". No processo argumentativo, sua atenção é voltada para o primeiro processo da leitura, ou seja, o perceptivo que induz, como já foi mencionado, apenas à representação visual da forma do texto, atitude introdutória e insuficiente para a formação do sujeito leitor. O leitor se obriga a evocar elementos constitutivos do processo cognitivo utilizando estratégias fincadas nas repetições, memorizações, tomadas de notas etc. Com essas estratégias, o sujeito leitor não busca seus conhecimentos prévios, mas se volta para respostas do Aqui está e nunca ou quase nunca as que mobilizem a relação implícita e fundada nos esquemas do leitor, ou as da categoria do Apenas você, aquelas que induzem o leitor a utilizar seus próprios conhecimentos. Em Letras,

\footnotetext{
a questão é ainda mais delicada em matéria de análise da argumentação e a extensão que se dá a este conceito. Numerosos textos literários se relevam: ensaios, os discursos (de Descartes ou de Rousseau, por exemplo), os textos polêmicos, os textos à tese. Para outros ainda (fábulas, contos filosóficos), os dados são ainda mais complexos. (AMOSSY, 2002, p. 23).
}

Desse modo a argumentação se vê reduzida a dados linguísticos racionalistas e sem problema algum. Mas utilizados nos textos literários, implica voltarmos ao século passado com um agir professoral com método tradicional pelo qual o texto literário é visto como suporte de ensino de regras gramaticais. Ora, argumentar, como diz Abreu (2011, p.25) é "a arte de convencer e persuadir (...) [onde] convencer é construir algo no 
campo das ideais, convencer alguém a pensar como nós [enquanto] persuadir é construir no terreno das emoções, é sensibilizar o outro para agir”. A argumentação utilizada com textos literários é reduzida a apenas esta função, além do mais, que a atitude de convencer alguém a pensar como nós... no ensino da literatura, lugar da diversidade por excelência... Deixa-se ao leitor deste artigo, refletir sobre...

Defende-se que desenvolver o processo argumentativo não é relevante para a leitura literária, nem levar o sujeito leitor a ver o texto literário em um modo único, nem fazê-lo buscar o senso comum... porque tal atitude favorece a ideia do pensamento único em literatura deslegitimando todo o sentido atrelado a esta palavra que por si só evoca polissemia. Ao contrário disso, o leitor comum pode até se beneficiar do processo argumentativo em sua leitura para investigar a organização da ordem do discurso segundo suas percepções. É um engajamento do leitor, na interação das informações levadas em conta na leitura, conduzindo-o a levantar hipóteses sobre o que está lendo, pois ele procede por predições, decepções e satisfações.

Ora, se o leitor age por predições, decepções e satisfações implica dizer que ele se volta para o seu mundo íntimo. Pergunta-se qual o lugar dos processos de leitura literária voltados para o mundo pessoal daquele que lê? Em outras palavras, onde fica a afetividade na aprendizagem?

\section{O processo afetivo na leitura literária}

O termo afeto vem do latim affectus significando estado, disposição da alma. Ele aparece no século XII como sinônimo de sentimento ou paixão. No fim do século XIX, o emprego deste termo se generaliza para traduzir em alemão affeckt empregado pela psicanálise a fim de designar uma carga emotiva entravando a liberdade de espírito e preocupando o equilíbrio psíquico do ser. A utilização deste termo atualmente lhe dá um sentido ainda mais estendido (CHEVALIER, 2002a, p. 6).

Mesmo que o termo afeto seja denotado negativamente e que se acorde à Poesia, sobretudo com Aristóteles, que definia o espetáculo em função da tragédia, duas principais emoções sentidas pelo espectador, tais como, o terror e a piedade, como diz 
Chevalier, (2002a, p. 6) "a filosofia moderna distingue os afetos, sentimentos irrefletidos e fugazes, como a cólera, das paixões duráveis e que se sujeitam à razão profunda, como o ódio”. Embora pareça existir uma dicotomia entre afeto e paixão, esses dois termos estão interligados. A questão da emoção, nos estudos da leitura literária é bastante importante, porém pouco desenvolvida. E como poderia ser estudada? O acolhimento das emoções sentidas nas etapas da leitura mencionadas na introdução deste artigo parece ser uma primeira pista.

É inegável que o leitor, constrangido à leitura obrigatória na escola, em contraste com a leitura voluntária feita em casa, apresente de modo espontâneo ou induzido, atitudes e interesses durante a leitura literária. O processo afetivo vai relevar da estrutura afetiva na qual o leitor apresenta demonstrando sua capacidade de riscos, do conceito de si em geral e de si como leitor e o seu medo do fracasso etc. Acrescente-se a isso, o desencadeamento de diversas emoções que passam despercebidas na maioria das vezes pelo docente no processo da leitura literária de seu discente.

Em 2006, organizado por Nathalie Blanc, um livro intitulado Emoção e Cognição é publicado. Ele é de base teórica da psicologia cognitiva, e bastante interessante, particularmente porque apresenta resultados de algumas pesquisas sobre o papel de emoções induzidas na leitura de textos literários e não focados apenas na cognição. Como diz Blanc (2006, p. 06) "se no século XX cognição rimava essencialmente com razão, neste início do século XXI, cognição rima com emoção”. Difícil e agradável de acreditar que o homem sabe raciocinar, mas igualmente sentir. Então, como articular a emoção e a cognição quando se pensa em leitura literária?

A leitura subjetiva pensada como um suporte teórico-metodológico acolhe as emoções sentidas do leitor comum no ato de ler. Entende-se por emoções sentidas aquelas experimentadas singularmente pelo leitor, são aquelas que o faz chorar de tristeza ou de alegria na passagem de um texto, ou ainda, aquelas que o faz rir em uma cena e outra. É pela emoção sentida que o sujeito leitor pode começar a sentir prazer em leitura porque ele se sente liberado para explicitar seus sentimentos. Enquanto problemática para o ensino da leitura literária, perguntamos: essas emoções são acolhidas durante esta atividade na escola? 
Infelizmente, quando se trata de emoção, o que aponta abundantemente a estatística são as emoções negativas, aquelas que dizem que alunos brasileiros não leem porque não gostam de ler. Por que leem pouco, notadamente Poesia. E quando se pensa em "didatizar" as emoções na leitura de textos literários, naquelas que surgem na medida que se lê um texto, como diz Blanc (2006, p. 123) "podem ser veiculadas ou pelos personagens ou pelas características estilísticas ou estruturais do texto, ou ainda pelo próprio leitor que vai reagir a sua maneira com a situação exposta no texto”. Os veículos desencadeadores das emoções são os personagens, a estrutura do texto e o próprio leitor. Se se amplia estes elementos para a poesia, os veículos desencadeadores são eu lírico, a forma do poema e o próprio leitor. As emoções do texto advêm à medida que o sujeito leitor vai avançando na história lida:

as emoções são sentidas por empatia pelo protagonista; por resposta direta a forma que dá o autor ao texto ou ainda representativas do estado que se encontrava o leitor antes mesmo da leitura, estado que não será, sem consequências sobre a compreensão das informações deliberadas no texto. (BLANC, 2006, p. 123).

Entende-se que tanto a empatia quanto a forma e o estado do leitor antes da leitura são relevantes. Quem leva em consideração esses elementos na leitura literária quando ensinada na escola? O primeiro ponto, ou seja, a empatia, e o segundo, o da estrutura do texto, são muito importantes. Porém, pensa-se agora um pouco mais com afinco, no terceiro ponto apresentado pela autora, a saber, o próprio leitor.

Quais consequências sobre a interpretação dada ao lido quando se depende do estado emocional do sujeito leitor anterior à leitura? Pensando nesse estado anterior à leitura literária na sala de aula, Thérien (2007) refletiu sobre o processo afetivo e o descreveu como o imaginário pessoal do leitor. Para que tal imaginário tenha seu lugar na escola, dever-se-ia acrescentar atividades de leitura literária pensadas com perguntas que permitissem ao leitor comum mergulhar em seu conhecimento prévio. Pensa-se que essa atitude no agir professoral favorece um melhor desenvolvimento do imaginário do leitor voltado para a criação e recriação do objeto de arte lido.

Definindo o imaginário como um conjunto de imagens representadas no espírito de um indivíduo ou de um grupo humano (AMON e BOMATI, 2002, p.230), essa 
definição releva da construção cultural, ética e moral de cada indivíduo ou sociedade na qual ele está inserido. As histórias que circulam através do texto durante a leitura não são neutras. Elas podem ser recebidas pelo leitor comum como um fluxo de emoções positivas ou negativas.

É graças ao processo afetivo que abre o pensamento para o entendimento de que toda compreensão que o leitor elabora no plano intelectual é acompanhada por uma elaboração afetiva. E, na leitura literária, se transforma em interpretação. A experiência de vida do sujeito leitor vai colorindo todos os aspectos de sua leitura. Como diz Thérien (2007, p. 30) "é a colocação progressiva de sua memória, lugar e espaço da experiência de integração e de prospecção". Compreende-se que o processo afetivo da leitura literária se apresenta como o espaço manifesto da imaginação do leitor, ativado durante a leitura.

Ressalta-se que a riqueza que desencadeia este processo, é que ele é alimentado pelos processos perceptivo, cognitivo e argumentativo, logo não faz mais sentido excluir a emoção, negando-a, na atividade leitora. Tudo se passa como se o leitor enquanto vaso pleno, pudesse enfim transbordar as emoções sentidas antes, durante e depois da leitura. O processo afetivo, como ainda diz Thérien (2007, p. 31) "informa mais a fundo, mais individual, mais singular que os processos perceptivo e cognitivo, mas a cor dada à leitura depende tanto, senão ainda mais, da constituição do sujeito, que da leitura que está sendo feita”.

Pelo processo afetivo, o sujeito leitor ativa sua memória-afetiva, que longe de ser um repositório compartimentado, aberto para sentir emoções advindas de sentidos já prontos, de leituras já dadas, a memória-afetiva pertence ao sujeito leitor, vem dele e se explicita pelas marcas subjetivas dele. Por isso, as leituras dadas, ou seja, com sentidos dados, longe de serem benévolas para o ensino, são limítrofes para um processo amplo, sugerido mais acima. Sendo assim, como diz ainda Thérien (2007, p. 30) "a imaginação aqui tratada, pertence ao poder de criação [do sujeito leitor] alimentada pelas paixões, emoções (...) situadas na relação entre o coração e os ritmos internos". Que professor tem o direito de tolher isso de seu aluno?

Mobilizar a implicação do leitor unindo a forma com o conteúdo pode favorecer um verdadeiro encontro entre seu imaginário com o do texto, podendo assim contribuir para um avanço na formação da leitura do texto literário. O resultado deste encontro 
com o sujeito leitor modificado, tornado outro, é definido com o nome de alterleitor (XYPAS, 2018) porque adquiriu outros saberes, outros conhecimentos.

O próximo processo Thérien (2007) chamou de integrativo agindo no plano social, processo cultural porque o sentido que se dá a uma leitura nunca está isolado. Ele parece reunir todos os outros processos anteriormente apresentados.

\section{O processo simbólico na leitura literária}

O processo integrativo age sobre o plano social. Este processo leva-se a pensar na leitura como linear e o leitor é levado a hierarquizar cada uma delas. Segundo Thérien (2007, p. 31) "a leitura dos jornais, a leitura da literatura e a leitura da Bíblia não são feitas em um mesmo contexto. A esse processo de integração e de hierarquização nomeamos de processo simbólico".

Entende-se o simbólico no ensino da leitura literária, como uma função e, como diz Cuq e Gruca (2017, p. 78) "um elemento central de renovação didática". Nesse sentido, a função simbólica da linguagem serve como elemento sintomático dos que leem, porque deixam suas marcas subjetivas no texto lido.

Assim, os resultados obtidos parciais ou globais da leitura advêm da relação do imaginário pessoal do leitor e do imaginário da sociedade na qual ele vive. Na escola, este processo é bastante visível, pois os leitores integram ou descartam, hierarquizam sempre o que leem dentro e fora da escola. Como diz ainda Thérien (2007, p. 31) "a leitura pode fazer descobrir uma ou mais figuras que para um dado leitor, constituirão a essência mesmo de sua experiência estética”.

Em que consiste esta experiência estética? Partindo do ponto que o ato de leitura nunca é isolado, o acolhimento dos sentidos construídos pelo leitor comum pode ser fundamentado com atividades de leitura que necessitem de perguntas voltadas para o conhecimento de mundo do texto e do mundo do leitor. Mas, qual dos processos anteriormente apresentados neste artigo, permitem a ressignificação do que se leu? Volta-se a mesma questão: O que o texto lido diz para o sujeito leitor? Ora, o que se sabe sobre isso nas práticas de ensino de leitura literária? É sine qua non que os processos 
afetivo e simbólico estejam imbricados para que formem a base da pirâmide da experiência estética de cada leitor.

Segundo Thérien (2007, p. 31) "sempre nessa relação indivíduo-sociedade, reconhece-se também as formas, conceitos, noções, valores e gostos que definem uma sociedade que se pode encontrar facilmente na leitura de jornais e ou nas das mídias”. Um encontro entre o saber coletivo do livro e o saber do sujeito leitor sugere que o ato de leitura, enquanto processos, é o meio pelo qual a leitura se nutre inevitavelmente, de valores, noções, conceitos, e com isso, clichês, estereótipos porque carrega as representações de dois mundos diferentes. Ainda, conforme Thérien (2007, p. 31) "este processo valoriza o fato de que os diferentes sistemas de signos possuam um valor referencial enquanto hierarquias, sistemas científicos, saberes, práticas, rituais, ideologias ou imaginários”. Os sentidos assim produzidos pelo sujeito leitor relevam não apenas da interface dos signos que compõem a obra, mas também de todo um referencial e estrutura psíquica que constitui a força interior, única, pessoal e íntima advinda do mundo subjetivo daquele que lê.

O ato de leitura no processo simbólico é bastante amplo. Ele vem reforçar as certezas que dão prazer ao leitor ou colocá-las em dúvidas pelas confrontações das diferenças, pela construção de sentidos formados por outros imaginários. Os sentidos são compartilhados pelo grupo social de origem do sujeito leitor e pelos seus pares. Isso pode fazer da atividade de leitura uma aliada contra o pensamento único em literatura. Assim, conclui Thérien (2007, p. 32) "o sentido que se pretende perfeitamente isolado estaria condenado a desaparecer". Por isso, no ensino da leitura literária, o professor não pode se contentar em dar ao aprendiz uma leitura pronta de textos literários. Não existe, portanto, um sentido em texto literário, mas sentidos pelos quais se comprovam a polissemia do lido. Como diz Barzeman (2015, p.18) “o simbólico não é apenas cópia ou representa a natureza - ele a transforma e cria significados”. São esses que vivificam a literatura e suas multiformas. Todo leitor evolui dentro de seu contexto cultural e toda leitura interage com a cultura e os esquemas dominantes atrelados a um meio e a uma época acumulando tudo isso a tal ponto, que se pode hoje em dia, se constatar transformação da leitura em determinadas sociedades e na vida pessoal do leitor comum. 
Enfim, os processos perceptivo, cognitivo, argumentativo, afetivo e simbólico acontecem concomitantemente na cabeça do sujeito leitor durante a atividade da leitura. Apresentá-los assim em partes, foi apenas uma tentativa de viabilizar cada um deles para o ensino da leitura literária. Os processos são complexos, mas podem guiar o docente a ensinar a leitura literária. Tudo é linguagem, e como tal, facilitadora da representação de objetos distantes no aqui e agora intersubjetivos (BAZERMAN, 2015a, p. 19).

\section{Considerações finais}

Na pergunta inicial deste artigo, como fazer para inovar o ensino da leitura literária, ao término da pesquisa bibliográfica feita em dicionários e artigos sobre o sintagma leitura literária, chega-se à conclusão de que a leitura literária difere da leitura de textos informativos. Ela é uma atividade que requer um sujeito leitor completo, ou seja, com cognição e emoção.

Os processos perceptivo, cognitivo, argumentativo, afetivo e simbólico da leitura literária demonstram muita complexidade, pois na cabeça do leitor nada é assim compartimentado. Mas, a leitura literária pode ser ensinada com tais processos em mente. Disto decorre que as perguntas devem movimentar a leitura dos textos literários para a compreensão dos processos interpretativos do sujeito leitor.

Constata-se que todos os processos são importantes entre si, mas eles não têm função idêntica para a análise da recepção da leitura. Como dito mais acima, os processos afetivo e simbólico são os mais abrangentes porque favorecem uma renovação no ensino da leitura literária e a explicitação do lado íntimo do sujeito leitor, quer dizer, de sua singularidade transformada com o lido.

Esse tema é bastante vasto e se compreende igualmente com ele que a formação de leitores de textos literários carece ainda de investigações para que se possa estabelecer um ensino sistemático. Ora, importante ressaltar que quando se pensa em ensinar a leitura literária, deve-se unir tal atividade à vida do sujeito leitor. Essencial mesmo não separar a atividade da vida dele, impondo-lhe, por exemplo, apenas uma possibilidade, 
uma leitura única, uma leitura dada, pronta que demande do sujeito leitor que ele marque um x na resposta certa. Contrariamente a esta atitude, tem-se aquela que pensa a leitura literária como incitadora de empatia, de projeção e de identificação, como também de inseguranças linguísticas. Ela impõe no mínimo ao docente, refletir sobre perguntas que mergulhem o sujeito leitor em construções de sentidos e não a limítrofe e estúpida "pesca" de respostas encontradas no texto.

Lançar mão dos processos e procedimentos é uma atitude abrangente no agir professoral. Contudo, uma luta sensata contra o pensamento único em literatura, podendo existir através de questões que visem ao reconhecimento de ideias, que instiguem a compreensão do leitor, que evoquem seus conhecimentos pessoais e façam fluir sua imaginação, que possam ser explícitas ou implícitas ou ainda fundadas nos esquemas mentais do leitor, contribuindo realmente como uma autoavaliação de seus processos interpretativos. Isso é fazer avançar o ensino com atividades de leitura como resposta a si, modos de ler e de ser.

Espera-se sensibilizar os futuros professores e/ou os professores para um ensino de leitura de textos literários diferenciado do ensino de leitura de textos informativos, demonstrando assim a necessidade da combinação de elementos singulares acima demonstrados para fazer avançar as reflexões sobre a formação de leitores literários proficientes.

\section{Referências}

ABREU, Antonio Suárez. A Arte de argumentar -gerenciando razão. E emoção. 13 impressão e $3^{\underline{a}}$ reimpressão ampliada, Atelier editorial, 2011.

AMON, É; BOMATI, Y. Lecture. In : Vocabulaire de l'analyse littéraire. Paris : Bordas, 2002, p. 261-262.

. Argumentation. In : Vocabulaire de l'analyse littéraire. Paris: Bordas, 2002, p. 50. AMOSSY, Ruth. Argumentation. In : Le Dictionnaire du littéraire. Paris: PUF, 2002. AURÉLIO. O Dicionário da língua Portuguesa. 8ª edição. Curitiba: Editora Positivo, 2010. 
BARZEMAN, Charles. O animal simbólico e a transformação cultural da natureza. In: Milton C. Mota; Angela P. Dionísio; Judith Hoffnagel (Trad.). Teoria da ação letrada, São Paulo: Parábola, 2015a, p. 11-28.

BENAC, Henri. Guide des idées littéraires. Paris : Hachette, 1988.

BLANC, Nathalie. Le rôle des émotions du lecteur en mémoire et compréhension de textes. In : Émotion et cognition - Quand l'émotion parle à la cognition. Paris : In Press, 2006, p. 123-140.

CICUREL, Francine. La lecture littéraire. Propositions pour une approche interactive, les Cahiers de l ADISFFLE n.3: Les enseignements de la littérature, Actes des $7^{\mathrm{e}}$ rencontres de janvier.

CHEVALIER, Jean-Frédéric. Affects. In - Le Dictionnaire du littéraire. Paris : PUF, 2002a. CUQ, Jean- Pierre. Dictionnaire des didactiques des langues étrangères. Paris: HachetteFLE, 2003.

CYR, Paul. Les classifications des stratégies d'apprentissage. In : Les Stratégies d'Aprentissage. CLE-International, 1998, p. 29-40.

DUFAYS, J-L et Dalmoni, B. Lecture litteraire In : Dictionnaire de didactique de la littérature. Paris : Honoré Champion, 2020, p. 75-78.

GIASSON, Jocelyne. La place des questions dans l'enseignement de la compréhension en lecture. In : La compréhension en lecture. Québec, Gaëtan Morin, 1990.

KLINKENBERG, Jean-Marie. Cognitif. Le Dictionnaire du littéraire. Paris : PUF, 2002a.

LOUICHON, B.; ROUXEL, A. Du corpus scolaire à la bibliothèque intérieure. Rennes : PUR, 2010a.

MACÉ. Mireille. Façons de lire, manières d'être. Paris : Essais Gallimard, 2011.

MARCUSCHI, Luis Antônio. Noção de sujeito e de subjetividade. In: Produção Textual, análise de gêneros e compreensão. $1^{\underline{a}}$ Edição, $7^{\underline{a}}$ impressão Rio de Janeiro: Parábola, 2008, p. 68-71.

MOISÉS, Massaud. Dicionário de termos literários. São Paulo: Cultrix, 2013.

REY, A. Le Dictionnaire Culturel en langue française, Paris : Éditions Le Robert, 2005.

ROY, Max. Lecture. In - Le dictionnaire du littéraire. (Org). ARON, P ; SAINT-JACQUES, D ; VIALA, A. Paris : PUF, 2002/2004, p. 338-340. 
THÉRIEN, Gilles. L'exercice de la lecture littéraire. In - GERVAIS, B. ; BOUVET, R. Théories et pratiques de la lecture littéraire. Presses de l'Université du Québec, 2007, p. 11-42.

WOOLF, Virgínia. Como ler um livro. In- $A$ arte do romance. São Paulo: L\&PM Pocket, 2019, p. 67-83.

XYPAS, Rosiane. A leitura subjetiva no ensino da Literatura - Apropriação do texto literário pelo sujeito leitor. Olinda: Nova Olinda, 2018.

. A biblioteca interior como prática contemporânea no ensino da literatura.

Revista Ecos, Mato Grosso, vol. 27, n.02, p.70-91, 2019.

Recebido em 24/04/2020.

Aprovado em 07/o5/2020. 